\title{
Evaluation of Prepubertal Patients with Suspected Neurosecretory Dysfunction of Growth Hormone Secretion: Diagnostic Steps and Treatment Response
}

\author{
Carmen Sydlik, Claudia Weißenbacher, Julia Roeb, \\ Susanne Bechtold-Dalla Pozza, and Heinrich Schmidt \\ Dr. v. Haunersches Children's Hospital, Department of Pediatric Endocrinology, \\ Ludwig Maximilians University of Munich, Munich, Germany \\ Correspondence should be addressed to Heinrich Schmidt; heinrich.schmidt@med.uni-muenchen.de
}

Received 10 October 2016; Revised 13 January 2017; Accepted 23 January 2017; Published 23 February 2017

Academic Editor: Massimiliano Ruscica

Copyright (C) 2017 Carmen Sydlik et al. This is an open access article distributed under the Creative Commons Attribution License, which permits unrestricted use, distribution, and reproduction in any medium, provided the original work is properly cited.

Background and Aims. Existence and diagnostic procedures of neurosecretory dysfunction of growth hormone (NSD) are still a matter of debate. The aim of our study was (a) to find out if prediagnostic auxological and laboratory data could serve as an indicator for pathologic and normal spontaneous GH-secretion and (b) to evaluate the response to GH-therapy in NSD-patients. Methods. Of 90 children (unicentric study) with normal response to GH-stimulation tests, in whom 12-hour night profiles for GHsecretion were performed, 49 were diagnosed with NSD (NSD group). Their auxologic data, IGF-I/IGFBP3-levels as well as the night profiles, were analysed and compared to those of the non-NSD group. Additionally, follow-up auxological data of the GH-treated NSD-patients were collected. Results. Prediagnostic auxologic and laboratory data did not differ between the two groups. Instead, for all analysed criteria of spontaneous GH-secretion (number of peaks, maximal and mean secretion) a significant difference was found. Children with NSD showed a good response to GH-treatment after $1(\Delta \mathrm{H}-\mathrm{SDS}+0,77 \pm 0,48)$ as well as 4 years $(+1,51 \pm$ 0,75). Conclusion. According to our results, analysing spontaneous GH-secretion remains the only method to identify NSD. Yet, as response to $\mathrm{GH}$-treatment is comparable to results in idiopathic GHD, it is worth to consider this diagnosis.

\section{Introduction}

Short stature is one of the most frequent reasons for consultation in pediatric endocrine units. Neurosecretory dysfunction of GH-secretion (NSD) is characterized by inadequate growth velocity, low to normal IGF-I-levels, and normal response of GH in stimulation testing but insufficient spontaneous GH-secretion [1-4]. A good benefit from treatment with recombinant growth hormone has been shown for these children [5]. Yet, the diagnostic process is strainful, in terms of cost, staff, and being time-intensive, as to current knowledge identification of NSD is only possible by measuring spontaneous GH-secretion for 24 or 12 hours [3, 6]. Moreover there is no general consensus which parameters (e.g., number and maximal amplitude of peaks, maximal and mean GHsecretion, and area under the curve) should be used for analysis of spontaneous GH-secretion [3, 6-10].
We were interested if the diagnostic process could be simplified, if certain prediagnostic data (before measuring spontaneous GH-secretion) actually used are predictive and if the characteristics used for analysis of this testing are good enough to distinguish between children with and without NSD. In addition, the outcome of GH-treatment and correlation with baseline auxologic and diagnostic features in patients classified positive for NSD should be evaluated with the aim to prove the correctness of the diagnosis.

\section{Patients and Methods}

In our institution between 03/2000 and 01/2015 spontaneous night 12-hour-secretion profiles of growth hormone were performed in 90 prepubertal children. Our institution laboratory used the same method for measuring GH, IGFI, and IGFBP3 over the whole study period (Immulite). 
TABLE 1: Prediagnostic auxological and laboratory data for the two study groups NSD and non-NSD ( $P$ values for the differences between the two groups; ANOVA analysis; $P$ value $<0,005$ for all parameters).

\begin{tabular}{|c|c|c|c|c|c|c|c|c|c|c|}
\hline & & $\begin{array}{c}\text { Age } \\
\text { (years) }\end{array}$ & $\begin{array}{c}\text { Weight } \\
(\mathrm{kg})\end{array}$ & $\begin{array}{c}\text { Height } \\
(\mathrm{cm})\end{array}$ & H-SDS & $\begin{array}{c}\mathrm{HV} \\
\text { (cm/year) }\end{array}$ & HV-SDS & $\begin{array}{c}\mathrm{dBA} \\
\text { (years) }\end{array}$ & IGF-SDS & IGFBP3-SDS \\
\hline \multirow{6}{*}{ NSD group } & $n$ & 49 & 47 & 49 & 49 & 49 & 48 & 49 & 47 & 45 \\
\hline & Mean & 9,73 & 22,94 & 120,85 & $-2,82$ & 4,32 & $-1,03$ & 1,60 & $-1,81$ & $-0,62$ \\
\hline & Median & 10,33 & 22,00 & 124,40 & $-2,75$ & 4,40 & $-1,36$ & 1,67 & $-2,00$ & $-0,71$ \\
\hline & SDS & 2,97 & 8,43 & 15,83 & 0,64 & 1,69 & 2,04 & 1,21 & 0,67 & 0,90 \\
\hline & Maximum & 14,52 & 43,60 & 150,0 & $-1,36$ & 8,60 & 2,80 & 5,17 & 0,18 & 1,82 \\
\hline & Minimum & 3,42 & 10,06 & 91,4 & $-4,18$ & 0,50 & $-5,37$ & 0,92 & $-2,96$ & $-2,21$ \\
\hline \multirow{6}{*}{$\begin{array}{l}\text { Non-NSD } \\
\text { group }\end{array}$} & $n$ & 41 & 40 & 41 & 41 & 41 & 41 & 40 & 41 & 39 \\
\hline & Mean & 10,42 & 24,39 & 125,18 & $-2,91$ & 4,76 & $-0,06$ & 1,82 & $-1,79$ & $-0,73$ \\
\hline & Median & 10,33 & 21,90 & 122,00 & $-2,92$ & 4,60 & $-0,87$ & 2,21 & $-1,78$ & $-0,70$ \\
\hline & SDS & 3,00 & 8,47 & 16,33 & 0,98 & 2,13 & 2,76 & 1,68 & 0,85 & 0,76 \\
\hline & Maximum & 16,00 & 45,10 & 159,0 & $-0,47$ & 12,2 & 2,90 & 4,67 & 0,26 & 1,01 \\
\hline & Minimum & 5,50 & 12,90 & 98,5 & $-6,35$ & 0,60 & $-3,79$ & $-3,50$ & $-3,02$ & $-2,57$ \\
\hline $\begin{array}{l}\text { Statistical } \\
\text { difference }\end{array}$ & $P$ value & 0,275 & 0,429 & 0,206 & 0,612 & 0,281 & 0,06 & 0,468 & 0,894 & 0,552 \\
\hline
\end{tabular}

For these "night profiles," blood samples were collected in 30-min-intervals from 08:00 p.m. to 08:00 a.m. Children fulfilling two of the following criteria were diagnosed as having NSD: number of peaks (i.e., significant rise of GH for at least 3 consecutive sample times) $<4$, maximal GHsecretion ("max") $<8,0 \mathrm{ng} / \mathrm{ml}$, and mean secretion ("mean") $<3,2 \mathrm{ng} / \mathrm{ml}$. By this, 49 children (male: female = 32:17) were classified having NSD and treatment with recombinant growth hormone was started. The 41 children (male: female $=25: 16$ ) with normal night $\mathrm{GH}$-secretion served as control group ("non-NSD group"). Children in whom puberty had already started (defined by Tanner stage $>$ B1 in girls and testis volume $>3 \mathrm{ml}$ in boys) as well as those with genetic syndromes or chronical illnesses and on medication which could possibly influence growth were previously excluded from the study.

For all children, the following data were analysed: age, weight, height, height-SDS (H-SDS), height velocity (HV), height velocity-SDS (HV-SDS), difference between chronological age and bone age (delay in bone age, dBA), IGF-I, and IGFBP3 at the time of the night profile or the latest available before. In all children classical GH-deficiency was excluded by normal results in growth hormone stimulation tests (clonidine and/or arginine test). As there were no significant sex-related differences in the all these parameters (data not shown), boys and girls were not analysed separately.

In NSD-patients, GH treatment (biosynthetic GH from Ferring, Ipsen, Lilly, Merck, Novo Nordisk, Pfizer and Sandoz) was started with a dose of $0,028 \pm 0,005 \mathrm{mg} / \mathrm{kg} / \mathrm{d}$ which was kept relatively constant afterwards (mean dose after 1 year: $0,030 \pm 0,003 \mathrm{mg} / \mathrm{kg} / \mathrm{d}$ ). To evaluate the effect of therapy, laboratory results for IGF-I and IGFBP3 (expressed in SDS) after 3 months of treatment as well as H-SDS, HV, and HVSDS after one year were obtained and differences to the pretreatment values were calculated $(\Delta \mathrm{H}-\mathrm{SDS}, \Delta \mathrm{HV}, \Delta \mathrm{HV}-$ SDS, $\triangle \mathrm{IGF}-\mathrm{I}-\mathrm{SDS}$, and $\triangle \mathrm{IGFBP3-SDS}$ ). For the NSD group, additionally long-term follow-up data of $\mathrm{H}$-SDS, $\mathrm{HV}$, and $\mathrm{HV}$-SDS were collected (mean follow-up: 3,9 $\pm 2,2$ years, range: 1 to 11 years). 1-year data existed for 42 of the 49 children. In the non-NSD group 3-month follow-up values for the laboratory parameters were available for 14 children, 1 -year height-data for 24 . Yet, as there were no further routine controls of these patients, it was not possible to get long-term follow-up data of this group.

The study protocol was approved by the ethics committee of the Ludwig-Maximilians-University, Munich, and written informed consent was obtained from the NSD-patients and their parents.

Statistical Analysis. For statistical analysis, the above mentioned anthropometric data of the patients were converted into sex-, age-, and height-specific standard deviation (SD) scores. Results are presented as mean \pm SD. For betweengroup comparisons (e.g., NSD versus non-NSD) we used Student's $t$-test or single factor variance analysis (univariate ANOVA) and in case of non-normally distributed variables the non-parametric Mann-Whitney $U$-test. Correlations between variables were determined by Spearman's method. Throughout, level of significance for each test was set to 0,05 . Calculations were performed using the statistical package SPSS for Windows (version 14.0, SPSS, Chicago, IL, USA) and R 2.12 (http://cran.r-project.org).

\section{Results}

3.1. Auxologic Data. First, we compared prediagnostic auxologic data of NSD- and non-NSD patients. Means, standard deviation, maxima and minima for age, weight, $\mathrm{H}-\mathrm{SDS}, \mathrm{HV}$, HV-SDS, and delay in bone age (dBA) for both groups are shown in Table 1. All children fulfilled the auxological indication criteria for considering disturbance of growth hormone secretion. We accepted this also for the two children who showed a quite high growth velocity (see Table 1: maxima in both the NSD- and the non-NSD-group) as they had grown so fast only in the last months before the night profile. There were no statistically significant differences for any one of the 
TABLE 2: Night profile data of NSD- and non-NSD patients.

\begin{tabular}{lcccccc}
\hline & $\begin{array}{c}\text { NSD } \\
\text { Number of } \\
\text { peaks }\end{array}$ & $\begin{array}{c}\text { Maximal } \\
\text { secretion } \\
(\mathrm{ng} / \mathrm{ml})\end{array}$ & $\begin{array}{c}\text { Mean secretion } \\
(\mathrm{ng} / \mathrm{ml})\end{array}$ & $\begin{array}{c}\text { Number of } \\
\text { peaks }\end{array}$ & $\begin{array}{c}\text { Maximal } \\
\text { secretion } \\
(\mathrm{ng} / \mathrm{ml})\end{array}$ & $\begin{array}{c}\text { Mean secretion } \\
(\mathrm{ng} / \mathrm{ml})\end{array}$ \\
\hline$n$ & 48 & 48 & 49 & 41 & 41 & 41 \\
Mean & 2,90 & 10,23 & 2,39 & 3,85 & 4,27 & 4,36 \\
Median & 3,00 & 9,15 & 2,40 & 4,00 & 0,60 & 4,20 \\
SDS & 1,13 & 4,14 & 0,54 & 0,99 & 6,58 & 0,88 \\
\hline
\end{tabular}

TABLE 3: Correlations of night profile data with prediagnostic auxological and laboratory data (Spearman's method). * would indicate a level of significance: $<0,05 ; * *$ would indicate a level of significance: $<0,01$. As there were no significant correlations, no asterisks are shown in the tables.

(a)

\begin{tabular}{|c|c|c|c|c|c|c|c|c|c|}
\hline & NSD patients & & H-SDS & $\mathrm{HV}$ & HV-SDS & Weight & IGF-I-SDS & IGFBP3-SDS & $\mathrm{dBA}$ \\
\hline \multirow{6}{*}{ Spearman-Rho } & \multirow{2}{*}{$\begin{array}{c}\text { Number of } \\
\text { peaks }\end{array}$} & $r_{S}$ & ,007 & ,126 & ,172 & 137 & ,136 & ,037 &,- 084 \\
\hline & & Significance & 960 & ,393 & ,247 & ,362 & ,368 & ,813 & ,568 \\
\hline & \multirow{2}{*}{$\begin{array}{l}\text { Maximal } \\
\text { secretion }\end{array}$} & $r_{S}$ & 059 &,- 024 & 101 & ,032 &,- 200 &,- 289 & 107 \\
\hline & & Significance & 691 & ,869 & ,499 & ,832 & , 182 & ,057 & ,468 \\
\hline & \multirow{2}{*}{$\begin{array}{c}\text { Mean } \\
\text { secretion }\end{array}$} & $r_{S}$ & ,064 &,- 013 &,- 032 &,- 244 &,- 105 &,- 149 & 0,366 \\
\hline & & Significance & 661 & ,927 & ,830 & ,098 & ,483 & ,327 &, 510 \\
\hline
\end{tabular}

(b)

\begin{tabular}{ccccccccccc}
\hline \multicolumn{2}{c}{ Non-NSD patients } & & H-SDS & HV & HV-SDS & weight & IGF-I-SDS & IGFBP3-SDS & dBA \\
\hline & Number of & $r_{S}$ &,- 010 &, 121 &, 062 &,- 204 &,- 022 &, 084 &,- 224 \\
\multirow{6}{*}{ Spearman-Rho } & peaks & Significance &, 949 &, 451 &, 698 &, 206 &, 889 &, 611 &, 164 \\
& Maximal & $r_{S}$ &,- 137 &,- 153 &,- 172 &, 090 &, 242 &, 045 &, 127 \\
& secretion & Significance &, 392 &, 340 &, 283 &, 579 &, 128 &, 788 &, 434 \\
& Mean & $r_{S}$ &,- 067 &, 011 &, 023 &, 069 &, 130 &, 111 &,- 131 \\
& secretion & Significance &, 677 &, 948 &, 887 &, 671 &, 417 &, 502 &, 419 \\
\hline
\end{tabular}

analysed parameters between the two groups (parts of these and following data were already shown in [11]).

\subsection{IGF-I and IGFBP3. In short children, IGF-I and IGFBP3} are used as surrogate parameters for $\mathrm{GH}$-secretion and testing for GH-deficiency is recommended when levels are below $-2,0$ SDS, although higher results do not exclude the diagnosis. In our collective, only $24(49,0 \%)$ of the children in the NSD- and $19(46,3 \%)$ of those in the non-NSD group showed IGF-I-values < -2,0 SDS. In 41 versus 33 (84 versus $80 \%$ ) they were lower than $-1,0$ SDS, yet in all but 1 patient in each group IGF-I was below 0 SDS (Figure 1).

For IGFBP3, we found values $<-2,0$ SDS only in 2 patients in each group and below -1,0 SDS in 16 NSD- and 14 nonNSD children $(33 \% / 34 \%)$. In $8 / 7$ patients $(16 \% / 17 \%)$, SDSlevels for IGFBP3 were above the mean of 0 SDS.

3.3. Night Profiles: Spontaneous 12-h-GH-Secretion. By analysing the 12-hour night profiles, in 27 children of the NSDgroup the combination of a low number of peaks and low mean secretion was found, 9 had subnormal maximal and mean secretion and in 9 all three criteria were pathologic. In the non-NSD group 15 of the 41 children $(36,6 \%)$ also had less than 4 peaks in their night profiles, but none of them showed maximal GH-levels below $8,0 \mathrm{ng} / \mathrm{ml}$ as well as mean $\mathrm{GH}-$ levels below 3,2 $\mathrm{ng} / \mathrm{ml}$.

Between the two groups univariate ANOVA-analysis revealed significant differences for the means of all three parameters (peaks: $2,9 \pm 1,10$ vs $3,8 \pm 0,98$, maximum: $10,2 \pm$ $4,10 \mathrm{ng} / \mathrm{ml}$ versus $18,3 \pm 3,50 \mathrm{ng} / \mathrm{ml}$, mean secretion $2,3 \pm$ $0,50 \mathrm{ng} / \mathrm{ml}$ versus $4,3 \pm 0,88 \mathrm{ng} / \mathrm{ml}$ ) [11]. In spite of this the ranges of the number of peaks in NSD- and non-NSD children widely overlapped (1-6 versus 2-7) and GH-maximum was normal in 23 NSD-patients. Mean secretion during the night was below the cutoff (i.e., $<3,2 \mathrm{ng} / \mathrm{ml}$ ) in every single one of the children classified having NSD, but in no one of the non-NSD group (Table 2 and Figure 2) [11].

3.4. Comparison of Night Profile Criteria with Pre-Diagnostic Parameters. For NSD- as well as non-NSD patients no significant correlations between the findings in the night profiles and any of the analysed prediagnostic parameters $\mathrm{H}-\mathrm{SDS}, \mathrm{HV}$, HV-SDS, weight, IGF-I-SDS, IGFBP3-SDS, and dBA were seen (Table 3 ). 


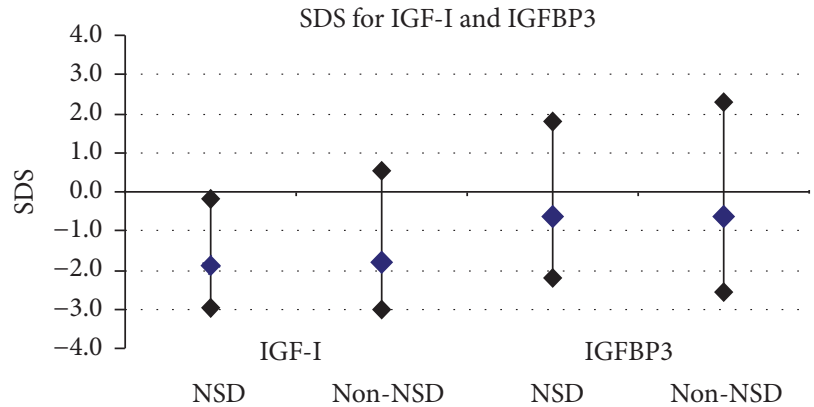

FIGURE 1: Prediagnostic auxological and laboratory data for the two study groups NSD and non-NSD ( $P$ values for the differences between the two groups; ANOVA analysis; $P$ value $<0,005$ for all parameters).
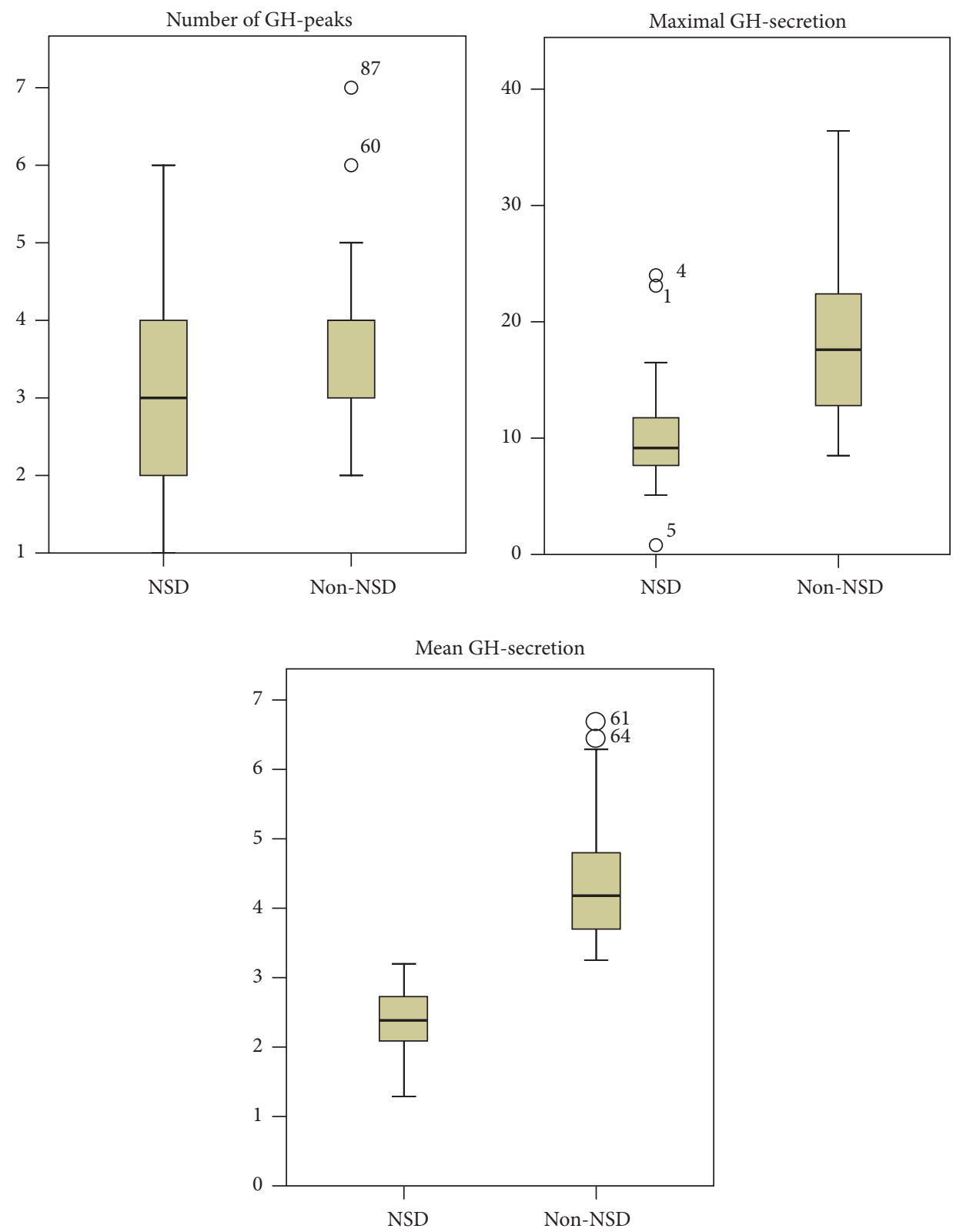

FIgURE 2: Night profile data of NSD- and non-NSD patients. 

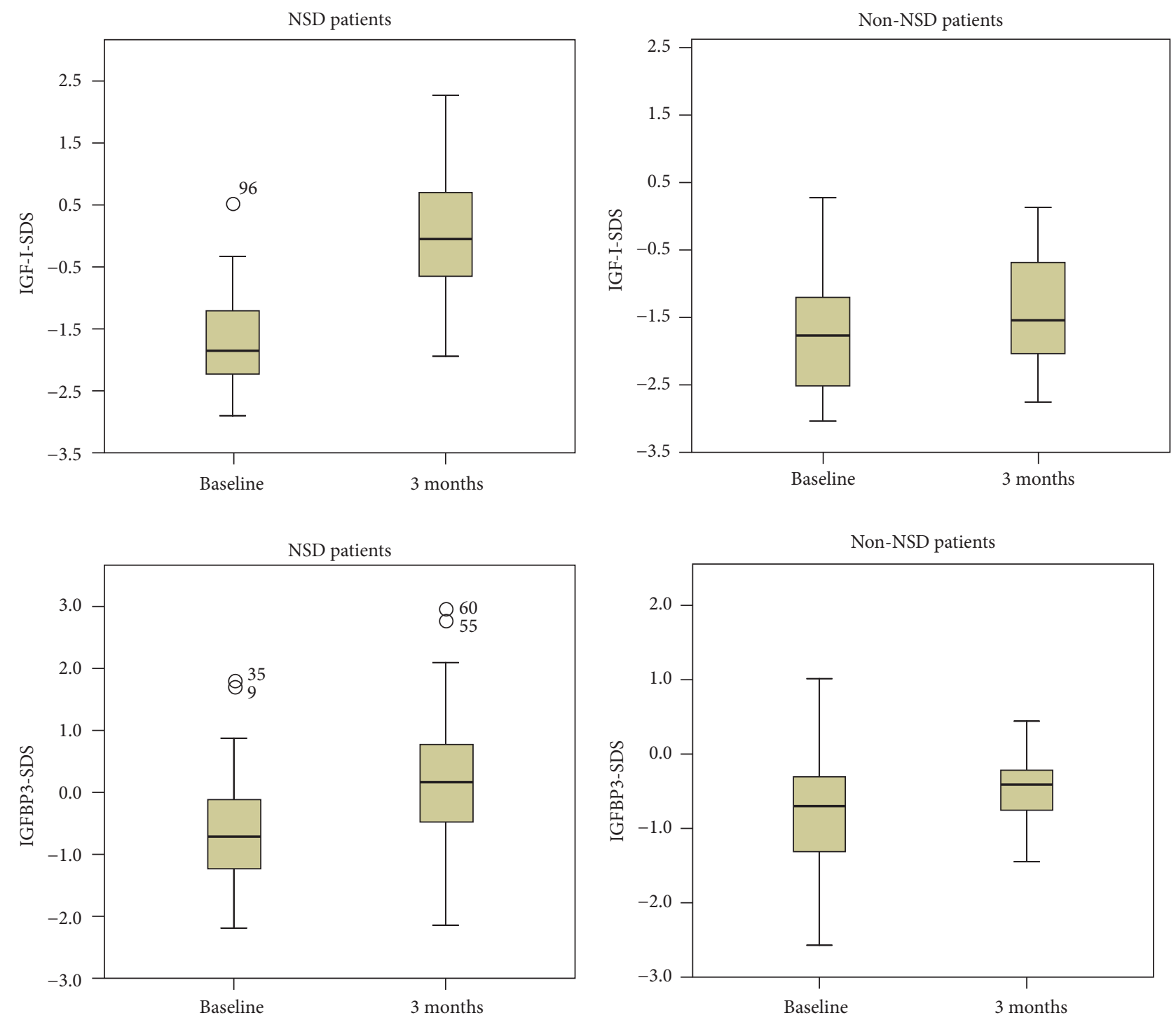

FIGURE 3: Change of IGF-I and IGFBP3 (in SDS) before diagnosis and 3 months after start of treatment/observation $(P$ value $<0,005$ in the NSD- and 0,194 in the non-NSD group).

\subsection{Response to Therapy}

3.5.1. IGF-I- and IGFBP3 after 3 Months and Growth Response after 12 Months of Treatment. Therapy with recombinant human growth hormone was started in all 49 children with NSD. To evaluate the response to growth hormone we studied changes in H-SDS and IGF-I-/IGFBP3-levels during therapy. An increase in IGF-I-SDS was seen in all children and mean IGF-I-SDS changed from $-1,80 \pm 0,67$ to $-0,26 \pm 0,99$, that is, more than $1,5 \mathrm{SDS}$ (Figure 3). For IGFBP3-SDS, changes varied widely (mean: $-0,62 \pm 0,90$ before treatment, $0,18 \pm$ 1,10 after three months). As expected, in the non-NSD group (no GH-treatment) there were no relevant changes for both IGF-I and IGFBP3 (Figure 3).

Generally growth data after one year of treatment with recombinant $\mathrm{GH}$ are regarded significant for the response to therapy also during the following years and for the final height outcome [11-19]. For our whole group of NSD-patients we found a mean gain of $\mathrm{H}$-SDS of $0,77 \pm 0,48$, HV almost doubled $(8,24 \pm 1,58 \mathrm{~cm} /$ year versus $4,32 \pm 1,68 \mathrm{~cm} /$ year at baseline) and HV-SDS increased by $4,40 \pm 3,5$. $\Delta \mathrm{H}$-SDS was $>0,5$ in 29 patients $(69 \%), \Delta \mathrm{HV}>3 \mathrm{~cm} /$ year in $27(64 \%)$, and $\Delta \mathrm{HV}-\mathrm{SDS}>1$ in $35(83 \%)$ after the first year of therapy (Figure 4).

3.5.2. Correlation of Night-Profile-Secretion with Response to GH-Treatment. Of special interest was to find out if there was a correlation between spontaneous GH-secretion in the night profiles and response to treatment. For the number of peaks and maximal GH-secretion, we did not find any significant association (Table 4). Mean GH-secretion was positively correlated with H-SDS after 1 year $\left(r_{S}+0,332\right)$ (but not with $\Delta \mathrm{H}$-SDS!) (Figure 5).

3.5.3. Comparison to Non-NSD Patients. We also compared the auxological data of the NSD-group after the first year 


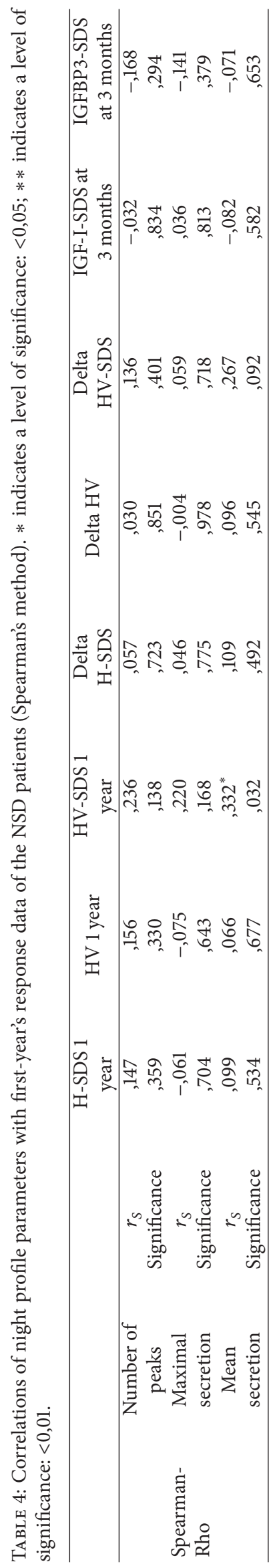



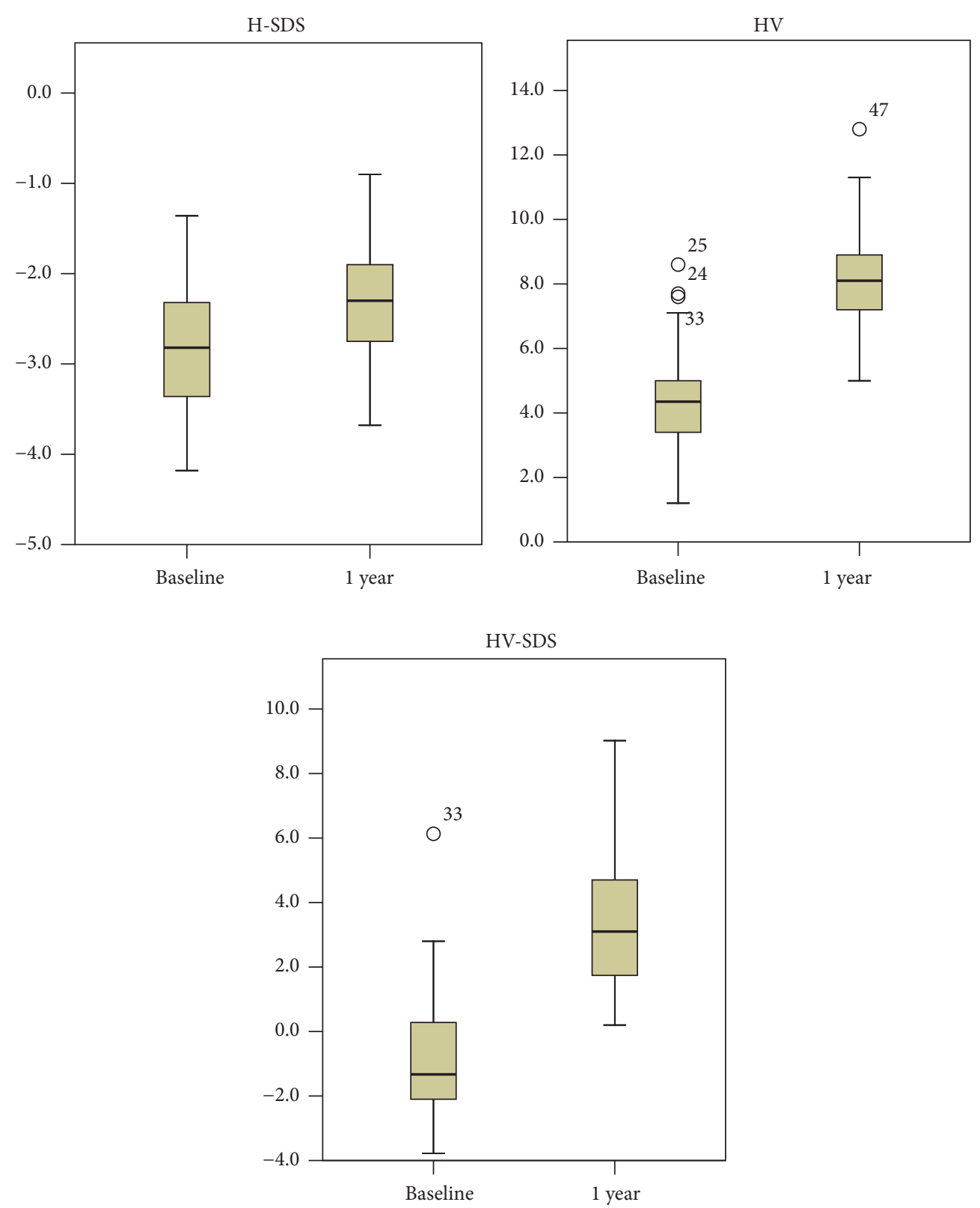

Figure 4: Auxological data before diagnosis and 1 year after start of treatment in NSD-patients.

of treatment with spontaneous growth of the non-NSD children. As there was no routine-follow-up of this group, data were available for only 24 of the 42 patients. While their auxological parameters had been quite similar to those of the NSD-group before (see above), now there was a wide discrepancy in absolute values for H-SDS, HV, and HV-SDS as well as in the change of these parameters during this year with high statistical significance (Figure 6). In contrast to the rise in the treated NSD-patients, we even saw a decrease in $\mathrm{HV}$ and HV-SDS in the control group in the mean, but with a wide range.

3.5.4. Follow-Up for Later Years. 15 of our patients already finished therapy having reached adult height. On the whole, their H-SDS raised from $-3,01 \pm 0,47$ to $-1,85 \pm 0,83$, which means an increase of $1,17 \pm 0,93$ SDS (Figure 7(a)). The evidence of these data for the real effect of the treatment is influenced by the fact that these patients started therapy at very different ages ( 6 to 14 years) and in consequence duration of treatment varied from 1 to 8 years. For our whole collective, mean follow-up time was 3,9 $\pm 2,2$ years. Data for at least these approximately 4 years existed for 25 children. After the peak during the first year of therapy, their mean height velocity continuously decreased $(8,24 \pm 1,60 \mathrm{~cm} /$ year after 1 year to $5,09 \pm 2,99$ after 4 years), but in spite of this, HV-SDS always remained positive $(3,56 \pm 2,30$ after 1 year to $0,77 \pm 1,92$ after 4 years). In consequence mean H-SDS increased with every year of treatment starting with $-2,81 \pm 0,64$ and reaching 


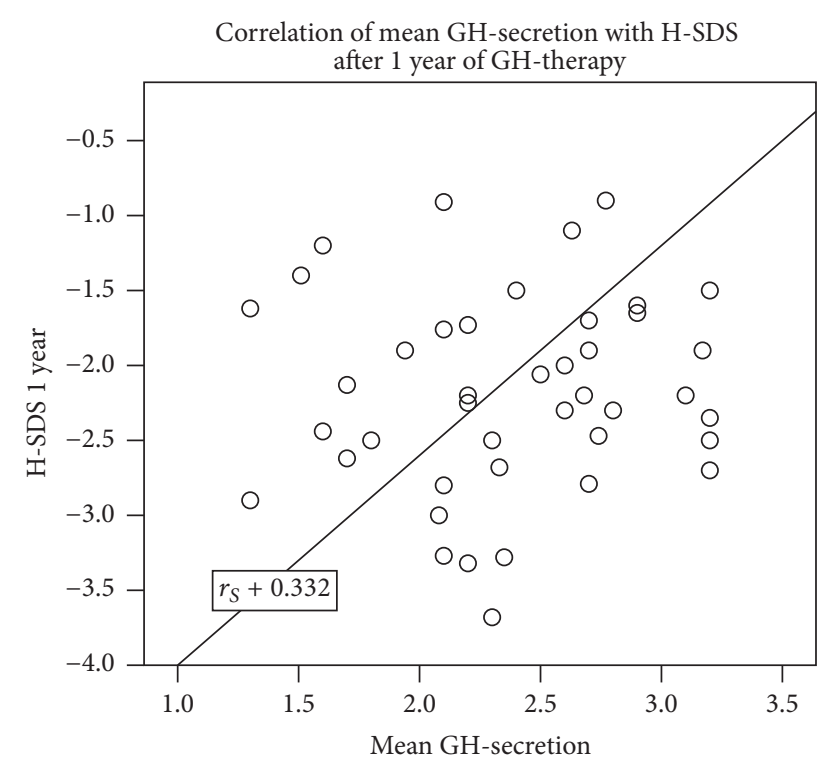

FIGURE 5: Correlation of mean GH-secretion ( $\mathrm{ng} / \mathrm{ml}$ ) with H-SDS after the first year of GH-treatment.

$-1,44 \pm 0,91$ after 4 years of treatment (i.e., increase of H-SDS of $1,51 \pm 0,75)$ (Figure 7(b)) [11].

\section{Discussion}

To our knowledge, this is the first study comparing two groups of children with and without the final diagnosis of NSD regarding their auxological, laboratory, and night profile data. We are also not aware of another analysis of an equivalent number of NSD-patients for their short- and longterm outcome under treatment with recombinant growth hormone. Among others, one of the most relevant limiting factors of our study is that nearly all correlations we found are rather weak.

In the first part of our investigations, we could demonstrate that using auxological data and laboratory parameters (IGF-I, IGFBP3) before analysing spontaneous GHsecretion, it was not possible to predict which children would finally fulfill the criteria for NSD. Concerning IGF-I it is of note that while in classical growth hormone deficiency levels lower than -2 SDS are considered as a hint for the diagnosis [20], just about half of the children in each of our two groups showed low values. In most of them, IGF-I-levels were below -1 SDS and in almost all below the mean. So, as it has been shown before [21], IGF-I-levels above 0 SDS can almost rule out the diagnosis of NSD. But in the whole, by regarding IGFI-levels it is not possible to distinguish children with NSD neither from those with normal results in the night profiles nor from children with classical GH deficiency.

Finally, the shown results of prediagnostic auxological and laboratory data, the growth hormone stimulation tests, and the night profiles confirm that evaluating spontaneous growth hormone secretion is the only method to identify children with NSD and in consequence remains necessary albeit strainful for patients, staff, and costs $[1,3,4,6]$. In agreement with other studies analysing 24-h-secretion for GHD-, NSD-, and normal children $[3,6]$, we found a significant difference in the number of peaks for the NSD- and non-NSD patients. In contrast to others who consider the number and amplitude of peaks as highly important [3], in our collective this criterion was not helpful for diagnosis of NSD in the individual child due to the widely overlapping results. The cutoff of $8,0 \mathrm{ng} / \mathrm{ml}$ for maximal $\mathrm{GH}$-levels shows a high specificity for differentiation between NSD- and non-NSD patients in our study. Nevertheless, in more than $40 \%$ of all NSD-patients a maximal GH-secretion in the same range as in the majority of the non-NSD patients was found, which makes sensitivity much lower. So similar to the number of peaks, the criterion of maximal GH-levels is not sufficient for the diagnosis as isolated parameter, as higher maximal GHlevels cannot exclude the existence of NSD in the individual child. Instead, mean secretion of GH with the cut-off-level of $3,2 \mathrm{ng} / \mathrm{ml}$ clearly remains the most specific and sensitive parameter in our study.

In all children with NSD, GH-treatment was started. Regarding the whole group, auxological data after the first year of therapy showed a good response $(\Delta \mathrm{H}-\mathrm{SDS}>0,5$ in $69 \%$ ). Our results for the increases of H-SDS, HV, and $\mathrm{HV}-\mathrm{SDS}$ as well as HV during the first year are comparable with or even higher than shown by many other studies for GH treatment in children with GHD [1, 18, 22-24]. A good response to GH-therapy in NSD-patients has already been reported 30 years ago [3] and was confirmed recently [25]. Moreover we can interpret it as a proof that our method of identifying children with NSD is correct.

Additionally, we saw significant differences to the spontaneous growth in the non-NSD group. In the mean, the growth velocity of the latter even decreased, but individual values varied widely which might be explained by an effect of age, but probably also by divergent reasons for their small stature; for example, familial or "real" idiopathic short stature, constitutional delay of puberty and growth, or others may be genetic reasons that were not diagnosed.

In spite of these generally positive outcome data of the NSD-patients, there is also quite a remarkable group of poor responders. Regarding a gain in $\mathrm{H}-\mathrm{SDS}<0,5$ during the first year of treatment which is the one of the criteria set up by Bakker et al. [12] used for defining poor response in most studies, about one third of our patients (31\%) did not reach this value. Yet this number is almost identical to the findings for GH-treated children with idiopathic GHD (IGHD), organic GHD (OGHD), SGA, and ISS [12, 25, 26]. Better outcome data were seen only for children with severe, but not with mild GHD [12]. For the parameters of spontaneous GHsecretion, that is, the specific criteria for identifying NSDpatients, there were no convincing correlations to the $\mathrm{GH}$ response.

Most relevant for children receiving GH-therapy is, of course, their final height. The patients of our NSD-collective who already finished therapy achieved a gain of $+1,17 \pm$ 0,93 SDS with $2 / 3$ of them showing an increase $>1,0$ SDS. Yet although this group represents almost one third of our collective, age at onset and time of therapy varied widely. 

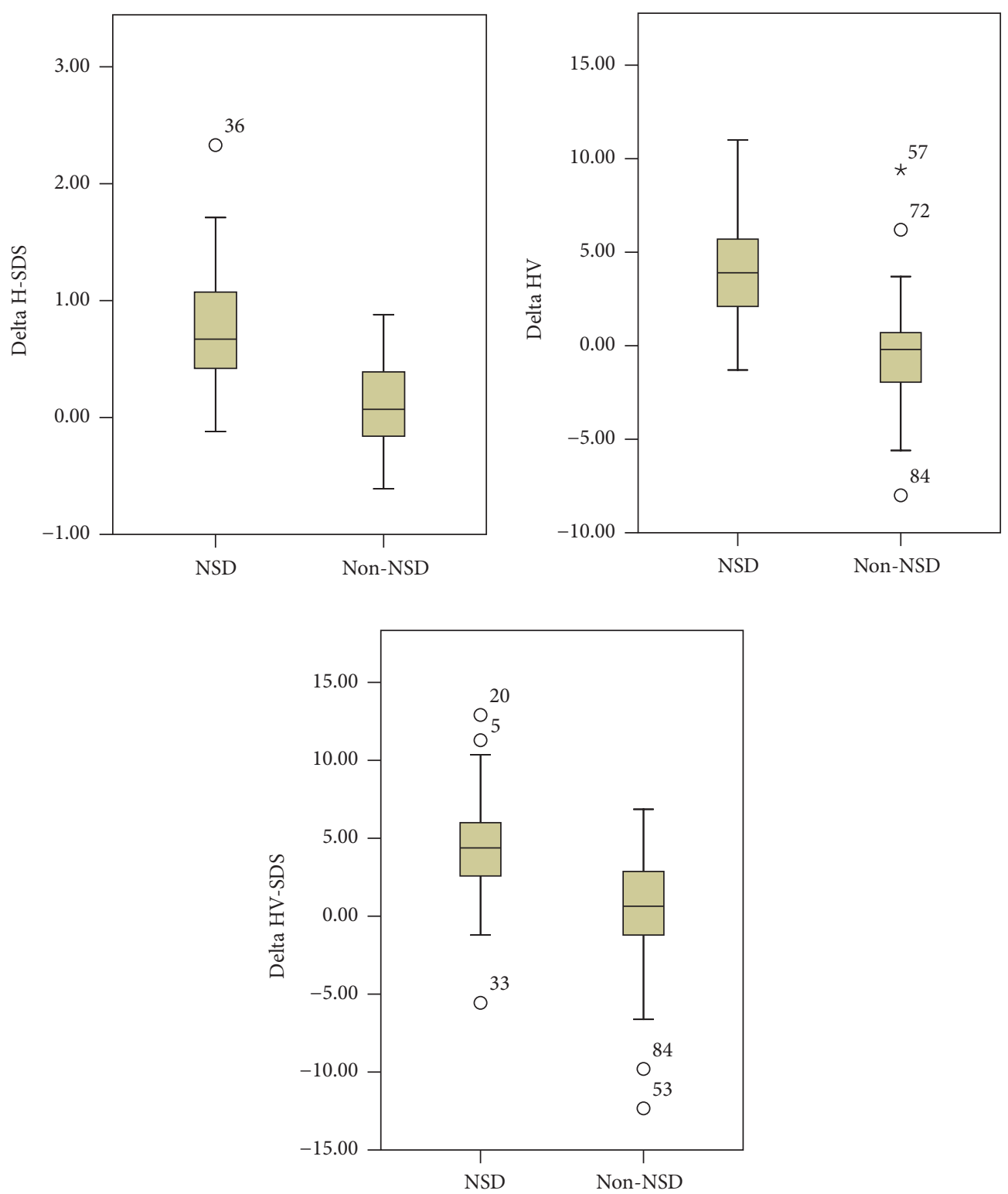

FIgURE 6: Changes in auxological data 1 year after diagnosis for NSD- (with GH-therapy) and non-NSD-patients (without therapy), $P$ value 0,00 (ANOVA-analysis) for all 3 parameters.

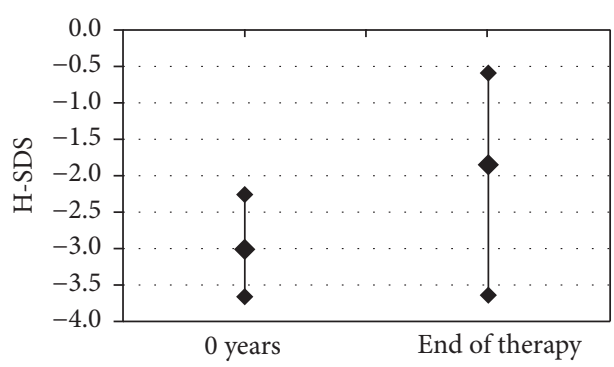

(a)

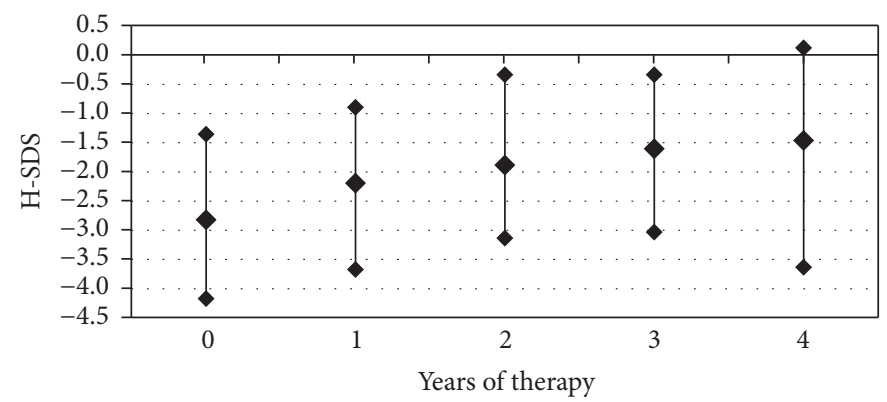

(b)

FIgURE 7: (a) Change in height from baseline to end of treatment in the patients who already finished therapy (mean, maximal and minimal levels); (b) change of height from baseline to 4 years of therapy in all children treated for at least 4 years. 
So we asked for further proof for the real effect of longterm GH-treatment in the NSD-patients. In consequence, we additionally analysed the group of children $(51,0 \%)$ who received treatment for longer duration than the mean of the whole group which was approximately 4 years. In these children, the mean height after this interval $(-1,44 \pm 0,91$ SDS) as well as the gain in height $(+1,51 \pm 0,75$ SDS $)$ was even higher. Analyses of the data of the large KIGS-study for near adult height showed just minimally better values for IGHD-patients $(+1,6$, range $+0,4$ to $+3,1$ SDS) [17], while in the ISS-patients of this large collective they were lower $(+1,1 \pm 0,2$ SDS $)[16]$, although for both groups, mean time of therapy was longer than in our NSD-patients. Another study of children treated with $\mathrm{GH}$ for 4,3 years in the mean because of short stature of different reasons (among others GHD and also NSD) found an increase of 1,2 $\pm 1,1$ SDS [27], which is almost identical with our patients who reached final height. Yet, our treatment group showed a better response after 4 years of therapy. In consequence not only 1-year outcome but also long-term outcome of our collective of NSD-patients is similar to or even better than that reported for other indications for GH-treatment [11]. Moreover, for the individual patient it certainly is of relevance to know that for the majority of patients treated for longer time and even for half of those with insufficient 1-year-response $(\triangle \mathrm{HSDS}<0,5)$, a final height of more than -2 SDS was achieved, which is regarded as "within normal height" for a population.

H-SDS after the first year was the most significant influencing factor for H-SDS after all the following years, which is in line with other reports [17], as after the first year, the youngest and smallest children had the best profit in height gain also later. Apart from that, their findings of $\Delta \mathrm{H}$ SDS during the first year as the most important predictive factor for long-term outcome and an additional relevance of age and height at start of treatment, duration of therapy, and midparental height (the latter not included in our analysis) correspond to ours.

\section{Conclusion}

In conclusion, comparing the two groups we did not find significant differences in prediagnostic auxological and laboratory analysis. Instead, only the night profile allowed a clear differentiation between NSD- and non-NSD-children. Thus performing 12-hour profiles of spontaneous $\mathrm{GH}$-secretion (especially mean GH-secretion) remains the only method to identify children with NSD and we could not find a possibility to reduce the prediagnostic procedures. Response to $\mathrm{GH}$ treatment of NSD-children is comparable to the results of $\mathrm{GH}$-therapy for children with growth hormone deficiency. $\mathrm{HV}$-SDS before start of treatment as well as $\Delta \mathrm{H}$-SDS during the first year of treatment are predictive for long-term effects of $\mathrm{GH}$ treatment.

\section{Disclosure}

This study was supported with an unrestricted research grant from Pfizer.

\section{Competing Interests}

The authors declare that they have no competing interests.

\section{Acknowledgments}

The authors thank Amalie Busch, Simone Kroke-Büsgen, and Eva Hoster for their help for conducting this study.

\section{References}

[1] R. G. Rosenfeld, K. Albertsson-Wikland, F. Cassorla et al., "Diagnostic controversy: the diagnosis of childhood growth hormone deficiency revisited," Journal of Clinical Endocrinology and Metabolism, vol. 80, no. 5, pp. 1532-1540, 1995.

[2] H. Schmidt, H. G. Dorr, O. Butenandt, A. Galli-Tsinopoulou, and W. Kiess, "Measurement of spontaneous, 12-hour sleepassociated GH secretion in prepubertal children with short stature: clinical relevance and practicability?" Hormone Research, vol. 46, no. 1, pp. 33-37, 1996.

[3] B. E. Spiliotis, G. P. August, W. Hung, W. Sonis, W. Mendelson, and B. B. Bercu, "Growth hormone neurosecretory dysfunction," The Journal of the American Medical Association, vol. 251, no. 17, pp. 2223-2230, 1984.

[4] Z. Zadik, S. A. Chalew, Z. Gilula, and A. A. Kowarski, "Reproducibility of growth hormone testing procedures: a comparison between 24-hour integrated concentration and pharmacological stimulation," Journal of Clinical Endocrinology and Metabolism, vol. 71, no. 5, pp. 1127-1130, 1990.

[5] Z. Zadik, S. A. Chalew, S. Raiti, and A. A. Kowarski, "Do short children secrete insufficient growth hormone?" Pediatrics, vol. 76, no. 3, pp. 355-360, 1985.

[6] Z. Zadik, S. A. Chalew, and A. Kowarski, "The definition of a spontaneous growth hormone $(\mathrm{GH})$ peak: studies in normally growing and GH-deficient children," Journal of Clinical Endocrinology and Metabolism, vol. 74, no. 4, pp. 801-805, 1992.

[7] K. Albertsson-Wikland and S. Rosberg, "Analyses of 24-hour growth hormone profiles in children: relation to growth," Journal of Clinical Endocrinology and Metabolism, vol. 67, no. 3, pp. 493-500, 1988.

[8] J. R. Kerrigan, P. M. Martha, R. M. Blizzard, C. M. Christie, and A. D. Rogol, "Variations of pulsatile growth hormone release in healthy short prepubertal boys," Pediatric Research, vol. 28, no. 1, pp. 11-12, 1990.

[9] J. Coste, M. Letrait, J. C. Carel et al., "Long term results of growth hormone treatment in France in children of short stature: Population, Register Based Study," British Medical Journal, vol. 315, no. 7110, pp. 708-713, 1997.

[10] G. L. Spadoni, S. Cianfarani, S. Bernardini et al., "Twelve-hour spontaneous nocturnal growth hormone secretion in growth retarded patients," Clinical Pediatrics, vol. 27 , no. 10, pp. $473-$ 478, 1988.

[11] C. Sydlik, C. Weißenbacher, J. Roeb, S. Bechtold-Dalla Pozza, and H. Schmidt, "Evaluation of prepubertal patients with suspected neurosecretory dysfunction for growth hormone secretion (NSD): diagnostic steps and treatment response," http:// abstracts.eurospe.org/hrp/0086/hrp0086P1-P633.htm.

[12] B. Bakker, J. Frane, H. Anhalt, B. Lippe, and R. G. Rosenfeld, "Height velocity targets from the national cooperative growth study for first-year growth hormone responses in short children," Journal of Clinical Endocrinology and Metabolism, vol. 93, no. 2, pp. 352-357, 2008. 
[13] P. Bang, S. F. Ahmed, J. Argente et al., "Identification and management of poor response to growth-promoting therapy in children with short stature," Clinical Endocrinology, vol. 77, no. 2, pp. 169-181, 2012.

[14] M. B. Ranke and A. Lindberg, "Observed and predicted growth responses in prepubertal children with growth disorders: guidance of growth hormone treatment by empirical variables," Journal of Clinical Endocrinology and Metabolism, vol. 95, no. 3, pp. 1229-1237, 2010.

[15] M. B. Ranke, A. Lindberg, P. Chatelain et al., "Derivation and validation of a mathematical model for predicting the response to exogenous recombinant human growth hormone $(\mathrm{GH})$ in prepubertal children with idiopathic GH deficiency," Journal of Clinical Endocrinology and Metabolism, vol. 84, no. 4, pp. 11741183, 1999.

[16] M. B. Ranke, A. Lindberg, D. A. Price et al., "Age at growth hormone therapy start and first-year responsiveness to growth hormone are major determinants of height outcome in idiopathic short stature," Hormone Research, vol. 68, no. 2, pp. 53-62, 2007.

[17] E. O. Reiter, D. A. Price, P. Wilton, K. Albertsson-Wikland, and M. B. Ranke, "Effect of Growth Hormone (GH) treatment on the near-final height of 1258 patients with idiopathic GH deficiency: analysis of a large international database," Journal of Clinical Endocrinology and Metabolism, vol. 91, no. 6, pp. 20472054, 2006.

[18] M. A. J. de Ridder, T. Stijnen, and A. C. S. Hokken-Koelega, "Prediction of adult height in growth-hormone-treated children with growth hormone deficiency," Journal of Clinical Endocrinology and Metabolism, vol. 92, no. 3, pp. 925-931, 2007.

[19] S. Straetemans, M. Roelants, M. Thomas, R. Rooman, and J. de Schepper, "Reference curve for the first-year growth response to growth hormone treatment in prepubertal children with idiopathic growth hormone deficiency: validation of the KIGS first-year growth response curve using the belgian register for the study of growth and puberty problems," Hormone Research in Paediatrics, vol. 81, no. 5, pp. 343-349, 2014.

[20] L. Duché, C. Trivin, W. Chemaitilly et al., "Selecting short-statured children needing growth hormone testing: derivation and validation of a clinical decision rule," BMC Pediatrics, vol. 8, pp. 29-36, 2008.

[21] A. Koch and H.-G. Dörr, "Insulin-like growth factor-I and its binding protein-3 in serum: are they good screening properties for the diagnosis of growth hormone deficiency?" European Journal of Clinical Chemistry and Clinical Biochemistry, vol. 35, no. 5, pp. 379-385, 1997.

[22] J.-P. Bourguignon, M. Vandeweghe, M. VanderschuerenLodeweyckx et al., "Pubertal growth and final height in hypopituitary boys: a minor role of bone age at onset of puberty," The Journal of Clinical Endocrinology \& Metabolism, vol. 63, no. 5, pp. 376-382, 1985.

[23] H. Jung, C. Land, W. F. Blum, and E. Schöenau, "Early differentiation between good and poor response to growth hormone therapy in short children born small for gestational age (SGA) to improve the outcome of poor responders," Journal of Pediatric Endocrinology and Metabolism, vol. 27, no. 3-4, pp. 229-235, 2014.

[24] H.-P. Schwarz, D. Birkholz-Walerzak, M. Szalecki et al., "Oneyear data from a long-term phase IV study of recombinant human growth hormone in short children born small for gestational age," Biologics in Therapy, vol. 4, no. 1, pp. 1-13, 2014.

[25] I. Iomo, A. Mussa, S. Vanelli, F. Feyles, S. Einaudi, and P. Matarazzo, "Comparison of baseline parameters and response to GH treatment in 125 children with short stature with eight different diagnosis," ESPE Abstracts, vol. 84, pp. 2-425, 2015.

[26] K. Albertsson-Wikland, A. S. Aronson, J. Gustafsson et al., "Dose-dependent effect of growth hormone on final height in children with short stature without growth hormone deficiency," Journal of Clinical Endocrinology and Metabolism, vol. 93, no. 11, pp. 4342-4350, 2008.

[27] J. Coste, M. Letrait, J. C. Carel et al., "Long term results of growth hormone treatment in France in children of short stature: population, register based study," British Medical Journal, vol. 315, no. 7110 , pp. 708-713, 1997. 


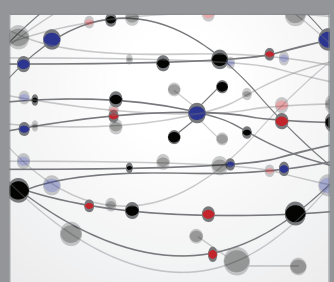

The Scientific World Journal
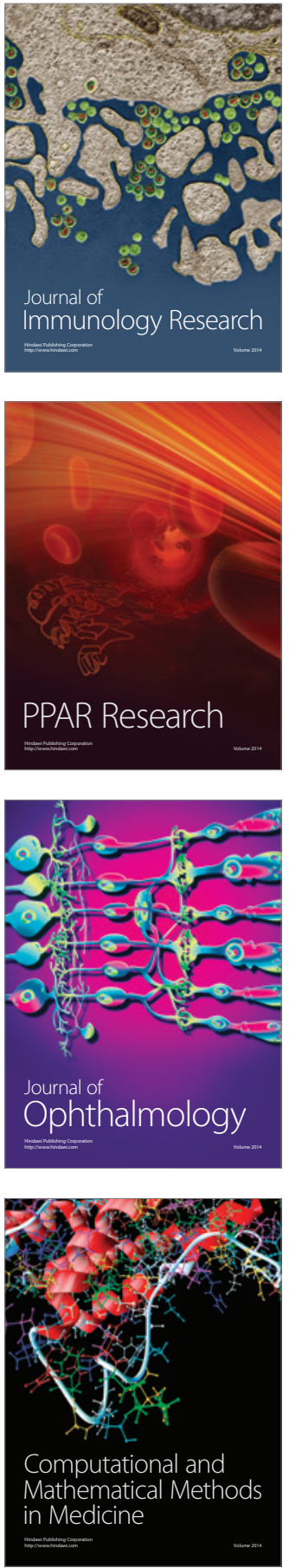

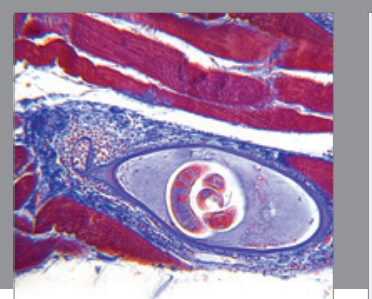

Gastroenterology Research and Practice
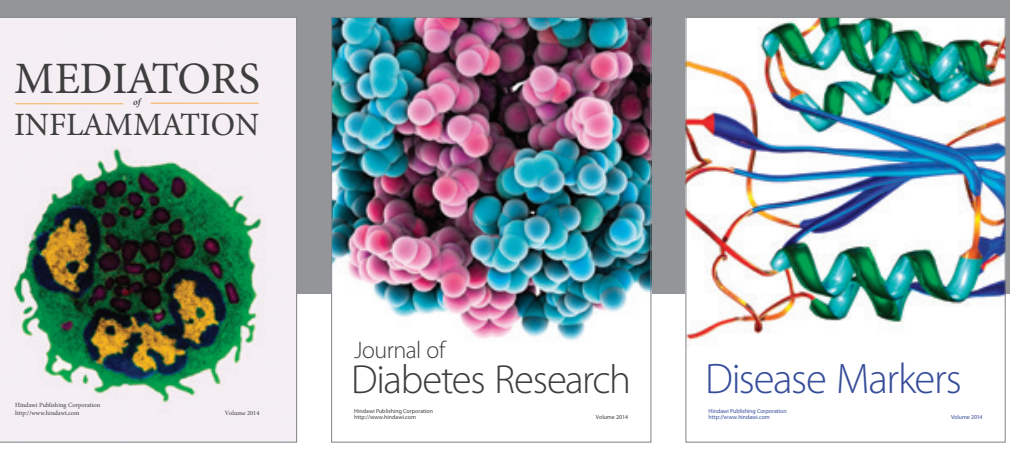

Disease Markers

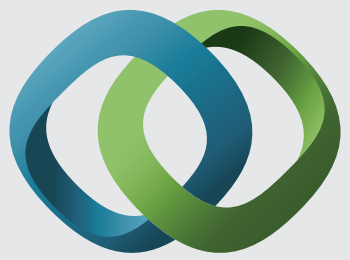

\section{Hindawi}

Submit your manuscripts at

https://www.hindawi.com
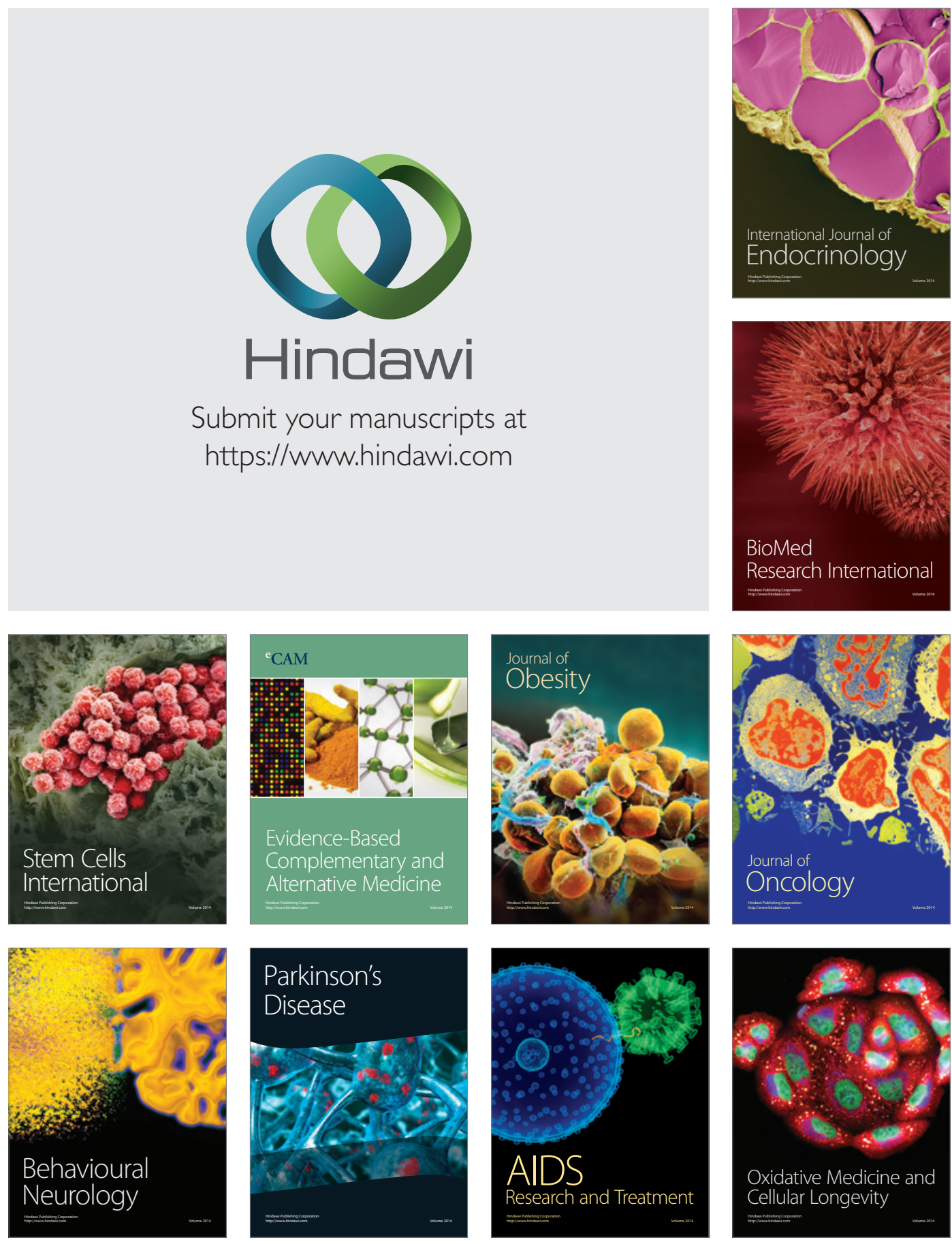